Valuation Studies 4(1) 2016: 1-9

\title{
Guest Editorial: Alternative Valuations
}

\author{
Ton Otto and Steffen Dalsgaard
}

This issue of Valuation Studies presents an anthropological take on 'alternative valuations'. The three articles in this issue stem from a workshop held in August 2012 at James Cook University in Cairns, Australia. The workshop was organized by the authors of this commentary along with Bruce Kapferer, and the focus was on Values of Dominance and Difference. The contributions came from anthropologists, sociologists and economists especially, and there was a strong focus on affairs that were relevant to an Australian audience at the time. One collection of contributions was later published in the Australian interdisciplinary journal eTropic with a focus on transvaluation and globalization (Dalsgaard and Otto 2014). The present contributions are all anthropological and were collected because they bring three distinct approaches to the theme of alternative valuations. On first sight the articles go in divergent directions but collectively and in relation to each other they illustrate present limitations as well as potential future directions of anthropological theorizing on value.

The 2012 workshop was a continuation and development of a workshop that was held in December 2011, also at James Cook University, entitled The Anthropology of Value. The aim of this earlier workshop was to explore the possibility of an anthropological theory of value. Whereas all participants agreed that value was a productive analytical lens through which to look at and describe certain cultural and social processes, opinions were starkly divided as to whether a distinct anthropological contribution to theory was possible and even desirable. The revised contributions have been published as two special issues of HAU: Journal of Ethnographic Theory, edited by Ton Otto

Ton Otto, University of Aarhus and James Cook University, ton.otto@cas.au.dk.

Steffen Dalsgaard, IT University of Copenhagen, sdal@itu.dk.

(C) 2016 Authors

LiU Electronic Press, DOI 10.3384/VS.2001-5992.16411

http://valuationstudies.liu.se 
and Rane Willerslev (2013a, 2013b). In the introduction the two editors represented the two main opposing opinions concerning the status and possible development of an anthropological theory of value (Otto and Willerslev 2013c). Willerslev maintained that anthropology's role was not to develop a grand theory about value but rather to wage a kind of intellectual guerilla warfare against major theories-as provided by other disciplines-based on concrete ethnographic cases that challenged existing assumptions and theoretical premises. Otto, on the other hand, argued that anthropology had contributed some important theoretical ideas to general social theory on value and that ethnographic fieldwork certainly could and should be an inspiration to theory formation, but conversely that field research was also productively inspired and driven by theoretical questions. The 2012 workshop from which the present collection derives engaged in a wider debate between disciplines and considered practical challenges resulting from conflicting principles of valuation. The present collection refers to this wider engagement, but takes up again the question of anthropological contributions to theories of value and valuation.

Anthropology has a long history of theoretical investment in value questions. Following the seminal and long-lasting influence of Marcel Mauss's work on The Gift (1990), numerous anthropologists have remained concerned with identifying cultural and social impulses in and to economic thinking and practice. Especially in recent decades this debate has been reinvigorated through a renewed focus on different approaches to the concept of value (e.g. Graeber 2001), or the opposition between notions of the singular and primarily economic 'value' and the plural and primarily cultural 'values' (Miller 2008). A dominant theme in these debates has been the role of the culturally implicit background of economic value and valuation. Some have drawn inspiration from Polanyi substantivism (e.g. Hann and Hart 2009) or Dumontian structuralism (Robbins 2013), while a longstanding voice such as that of Marshall Sahlins (1976, 2013) has argued since the 1970s that western economism itself is a particular cultural form of reasoning.

Anthropological approaches to value and valuation are naturally impacted by the way the term is also a key analytical concept in the social sciences more generally, even if its meaning and application vary widely according to discipline and field of study. In a simplifying but still valid way one can distinguish between (at least) three social domains that are treated differently. In the cultural-religious domain, values are part of the identification of ethnic and religious groups who distinguish themselves by their different worldviews and cultural practices. In the political domain, values-such as human liberty, democracy, security, well-being-are considered as the basis for political organization and policymaking. Finally, the economic domain 
focuses on the production of wealth and specializes in the measurement of value to allow for the comparison and exchange of different things and practices (including labour).

There is extensive scholarship on the historic development and hierarchical relationship between these domains or spheres, for example Louis Dumont's (1977) analysis of the emergence of an economic ideology in the West that diverged from and later dominated religious and political ideologies, and Bruce Kapferer's more recent work on the emergence of the corporate state, which is subordinated to and controlled by the terms of the market (e.g. 2010).

Needless to say, no matter how such spheres are conceptualized and defined, they will frequently overlap, and both past and recent anthropological work has been concerned with identifying their interrelationships, including for instance how economic valuation is symbolically constituted (Sahlins 1976); how commodification and the 'individualized' entrepreneurial action praised by neoliberal economics depends on relational factors such as kinship (Elyachar 2005), or on gift-giving and reciprocity (Tsing 2015); or how political 'values' and objects of governance become organized through numerical rankings and indicators (Shore and Wright 2015). The role of economic performativity stressed by scholars focusing on science and technology studies (e.g. MacKenzie et al. 2007) has furthermore begun to gain influence in anthropological studies of the (communicative) making of the economy (e.g. Holmes 2014).

Anthropological theorizing has remained concerned with two key questions, where value conflict and/or domination come to the fore.

First, there is the question of the underlying model of society that we use. Since the birth of the social sciences, scholars have argued over the extent to which 'society' is primarily based on a consensus of values or rather on difference and negotiated conflict. Is it vital for a sustainable society to have a hierarchy of values in place or is it necessary and possible to accommodate an ongoing process of value negotiation and conflict? This is a crucial issue in today's world, where value differences are often represented as fundamental and nonnegotiable-cf. Samuel Huntington's idea of a 'clash of civilisations' (1996). Value conflicts occur not only between nations and ethnic groups but are also part of the political process within modern (corporate) states. The 'Occupy Wall Street' movement was a case in point demonstrating the development and expression of antihegemonic values across the western world. The strong division caused by the 2007-2008 so-called 'Intervention' in Australia also highlighted the potential contradictions between core political values such as the human right to freedom and the state's obligations to protect human life (security) (Sutton 2009; Lattas and Morris 2010).

The second key concern, which is the one the articles in this issue are addressing in different ways, is whether practices of the market 
and the state implicitly create a hierarchy of values that is no longer discussed and thus constitutes a hegemonic environment that silences alternative valuations. We refer to the development of universal standards of value measurement, such as money, in the market economy and corresponding measures of categorization and enumeration practised by modern states to map, monitor, control and service their citizens. Both complexes, market and state, imply a drive to totalizing systems of comparison and control that set the tacit background for more explicit discussions and conflicts about value (such as engaged by the Occupy movement). As a reaction to and correction of the dominance of monetary value standards, alternative measurements systems are being developed to support policy decisions such as the 'quality of life', 'social quality' and 'social well-being index'. But the premises on which these alternative standards are based often still appear to reproduce basic assumptions of the economic model.

In the invitation, the contributors to the Cairns workshop were asked to address the following two questions in particular.

1. In view of the power as well as the obvious limitations of monetary systems for comparing and measuring different kinds of values, is the development of alternative systems for comparing and quantifying values such as 'quality of life' or 'social wellbeing' a viable and desirable solution or rather the reproduction of a biased model, that excludes alternative forms of valuation?

2. How can societies deal with different value systems in a way that does not lead to the total domination of one system by another? Can we design political institutions that make it possible to discuss, negotiate, and even generate value differences both within and between political, economic and cultural units?

The articles in this collection thus explore and present studies of systems where there are qualitative and political contests between different and alternative values and valuation forms, and especially reactions to the attempt to realize one dominant system of valuation whether it is quantified estimations of carbon (non)emission, market exchange or appreciations of biodiversity.

Simon Foale, Michelle Dyer and Jeff Kinch's contribution deals with the question of how biodiversity is valued by different groups of users and stakeholders. Their regional focus is on rural Melanesia in the South Pacific and here they observe a stark contrast between the valuation by transnational conservationists on the one hand and Melanesian subsistence farmers and fishers on the other. Whereas the former ascribe an intrinsic value to biodiversity, based on biological and philosophical assumptions about the irreplaceable value of individual species, the latter have a more pragmatic attitude towards the species existing in their environment based on their need to sustain a livelihood in it. The opposition is evident and in order to convince 
rural Melanesians to support conservationist agendas, the transnational conservationists try to argue for the local economic value of biodiversity. These arguments however do not carry much persuasive power for people who experience in daily subsistence practice that a reduction of the species they use can actually lead to greater yield and return on their energy input.

From a comparative-theoretical perspective, the interesting issue in this conflict of valuations is in the way the authors interpret the different value perspectives. Whereas western transnational conservationists appear to base their valuation on ideological premises, Melanesians are presented as taking a more praxis-oriented approach prompted by the demands of living in a certain environment. This opposition is reminiscent of Sahlins's famous discussion of two main strands of theorizing in anthropology: a focus on culture versus a focus on practical reason (1976). In Sahlins's view anthropologists have made a faulty opposition between the West and the Rest. Whereas non-western societies have been interpreted as being dominated by culture, the West is depicted as driven by other forces that are summarized under the term 'practical reason', which includes economic development and technological adaptation. Sahlins's key argument is that the apparent economism of the West in fact is a form of cultural reason as well. For example he contends that the motivation to gather interest on money, a key capitalistic principle, is not based on a universal drive for maximization but is rather engendered by a culturally defined value. Thus western societies are as much culturally grounded as non-western ones (see also Sahlins 2013, 2015).

The case presented by Foale, Dyer and Kinch appears to turn Sahlins's argument on its head. While the global conservationists are portrayed as being motivated by cultural valuations of nature, Melanesian farmers are depicted as pursuing a practical logic of adaptation and maximization of effort. Foale et al. argue that conservationists have to take these practical considerations into account, when they are dealing with local populations in Melanesia. Does their finding indicate that the West has turned to cultural reason in its relation to nature, while non-western societies should be seen as sustaining more utilitarian concerns? This is of course a simplified reading of the carefully argued and richly documented article by Foale, Dyer and Kinch, but the article clearly shows that Sahlins's dichotomy is still relevant to think with. Do cultural values uphold a certain autonomy and arbitrariness as cultural systems in relation to the objective world they mediate, or are they imbued with practical determinants deriving from human action in a social and natural environment? And what happens when people guided by different principles of valuation try to persuade and influence each other? Are 
there ways to create a common language to discuss and compare the value of the different interests?

Dealing with an ethnographic case from Mozambique, where market women engage in some form of reciprocal relations with subterranean dwarfish twins to increase their sales, Bjørn Bertelsen can be seen to take the opposition between culture and practical reason in another direction. At face value he appears to be caught in the same dualism, between an economic (practical reason) understanding of value and a cultural one. He acknowledges the presence of both kinds of valuation, but argues against an implicit or explicit assumption among many analysts, that cultural valuations are dominated by or encompassed by the encroaching value logic of the market. For example, he criticizes Comaroff and Comaroff's concept of 'occult economies' for implying the dominance of capitalism in African societies where witchcraft and other 'occult' practices are interpreted as constituting the dark underbelly of capital itself (Comaroff and Comaroff 1999). According to Bertelsen one needs to accept that there are two different systems at play, without any one being dominant over the other. So it appears that Bertelsen, in contrast to Foale et al., defends the continuing importance and vigour of cultural reason in non-western cultures in contrast to the practical western market logic.

In an apparent return to older theoretical positions, the critical contribution that Bertelsen is making lies in his understanding of cultural value as an expression of human generativity. The ethnography of the reciprocal but also mutually exploitative relations between the market women and the dwarf couple can be interpreted from the point of view of the valuation of generativity. Bertelsen finds theoretical support for this perspective in David Graeber's important book Toward an Anthropological Theory of Value (2001), which considers 'creative potential' as the key to understanding value. Moreover, Bertelsen links this understanding of value to Deleuze's concept of the virtual as a component of the real, in addition and contrast to the actual. The virtual component of reality can become actualized in tangible phenomena through human action. Interestingly, Bertelsen finds additional inspiration in the philosophy of Cornelius Castoriadis with its focus on social transformation, human autonomy and self-creation. Here we are at the brink of a new understanding of culture as a continuously creative endeavour that builds on virtual realities as much as on actual ones.

Steffen Dalsgaard's article on the emergence of carbon valuations allows us to extend this line of thought on the basis of alternative cultural forms of valuation that are actually emerging globally. Carbon value can be seen as a way for states and other institutional actors to direct and stimulate desired behaviour. So far there is nothing new. The truly interesting development is that carbon value makes a claim to be able to compare actions and non-actions, things and non-things. In 
other words: actualities and virtualities. In carbon valuation the descriptions and measurement of alternative worlds-such as the nonuse of forest resources when exploitation is planned-are brought into play to measure and impact upon the actuality. One could argue that by including the virtual in the very measurement of value, carbon valuation is a generative form of value. This appears to go beyond the opposition between culture and practical reason, because it opens up for the emergence of new systems of valuation that include both the aspect of practical reason in relation to perceived threats and necessary adaptations, and the aspect of cultural reason through the value of generativity. Through this inclusion of the virtual in the valuation of the actual, culture can no longer be considered as an autonomous and arbitrary tertium quid between the human subject and the objective world as in Sahlins's original theoretical framework (1976), but it should rather be understood as a subject-driven interface that may transform society through the generation of new forms of valuation.

We expect that a focus on the potential generativity of cultural forms is a productive way to advance the anthropological theory of value, by including the virtual in the evaluation of the actual. Not only does such theory allow for an alternative understanding of social change and the emergence of new institutions. It might also better equip anthropologists to participate in productive multidisciplinary discussions about alternative systems of valuation, such as quality-oflife and carbon credits.

\section{References}

Comaroff, Jean, and John L. Comaroff. 1999. "Occult Economies and the Violence of Abstraction: Notes from the South African Postcolony." American Ethnologist 26(2): 279-303.

Dalsgaard, Steffen, and Ton Otto. 2014. "Value, Transvaluation and Globalization." eTropic 13(2): 1-6.

Dumont, Louis. 1977. From Mandeville to Marx: The Genesis and Triumph of Economic Ideology. Chicago, IL: University of Chicago Press.

Elyachar, Julia. 2005. Markets of Disposession. Durham, NC: Duke University Press.

Graeber, David. 2001. Toward an Anthropological Theory of Value: The False Coin of Our Own Dreams. New York: Palgrave.

Hann, Chris, and Keith Hart (eds). 2009. Market and Society: The Great Transformation Today. Cambridge: Cambridge University Press.

Holmes, Douglas. 2014. Economy of Words. Chicago, IL: University of Chicago Press.

Huntington, Samuel P. 1996. The Clash of Civilizations and the Remaking of World Order. New York: Simon \& Schuster. 
Kapferer, Bruce. 2010. "The Aporia of Power. Crisis and the Emergence of the Corporate State." Social Analysis 54(1): 125-151.

Lattas, Andrew, and Barry Morris, 2010. "The Politics of Suffering or the Politics of Anthropology." In Culture Crisis: Anthropology and Politics in Aboriginal Australia, edited by J. Altman and M. Hinkson, 61-88. Sydney: UNSW Press.

MacKenzie, Donald, Fabian Muniesa, and Lucia Siu (eds). 2007. Do Economists Make Markets? On The Performativity of Economics. Princeton, NJ: Princeton University Press.

Mauss, Marcel. 1990. The Gift. London: Routledge.

Miller, Daniel. 2008. "The Uses of Value.” Geoforum 39: 1122-1132.

Otto, Ton, and Rane Willerslev (eds). 2013a. Value as Theory. Part I of II. Special Issue of HAU: Journal of Ethnographic Theory 3(1): 1-171.

- (eds). 2013b. Value as Theory. Part II. Special Issue of HAU: Journal of Ethnographic Theory 3(2): 1-243.

- 2013c. "Introduction. 'Value as Theory': Comparison, Cultural Critique, and Guerrilla Ethnographic Theory." HAU: Journal of Ethnographic Theory 3(1): 1-20.

Robbins, Joel. 2013. "Monism, Pluralism, and the Structure of Value Relations: A Dumontian Contribution to the Contemporary Study of Value." HAU: Journal of Ethnographic Theory 3(1): 99-115.

Sahlins, Marshall. 1976. Culture and Practical Reason. Chicago, IL and London: University of Chicago Press.

- 2013. "On the Culture of Material Value and the Cosmography of Riches.” HAU: Journal of Ethnographic Theory 3(2): 161-195.

- 2015. "An Anthropological Manifesto." Anthropology Today 31(2): 8-11.

Shore, Cris, and Susan Wright. 2015. "Governing by Numbers." Social Anthropology 23: 22-28.

Sutton, P. 2009. The Politics of Suffering. Melbourne, VIC: Melbourne University Press.

Tsing, Anna. 2015. The Mushroom at the End of the World. Princeton, NJ: Princeton University Press. 
Ton Otto is professor of Anthropology at Aarhus University, Denmark, and professor and research leader at James Cook University, Australia. Currently he is also the head of the Ethnographic Department at Moesgaard Museum, Aarhus. Based on long-term ethnographic field research in Papua New Guinea he has published widely on issues of social and cultural change. His interests comprise the epistemology and methodology of ethnographic research, including visual and museum anthropology, and its relationship to innovation, intervention and design. His recent publications include the co-edited volumes Experiments in Holism: Theory and Practice in Contemporary Anthropology (Wiley-Blackwell 2010), Design anthropology: Theory and practice (Bloomsbury 2013), Value as Theory (Special issue HAU 3 (1 and 2), 2013) and Design Anthropological Futures (Bloomsbury 2016).

Steffen Dalsgaard holds a PhD in Anthropology and Ethnography and is associate professor in the research group Technologies in Practice at the IT University of Copenhagen. He has worked with perceptions of the state and government in Papua New Guinea, with the cultural aspects of electoral systems and politics, and more recently with the logic of carbon trading. Among his most noteworthy recent publications is the co-edited volume Time and the Field (Berghahn 2015), which rethinks the notion of the ethnographic fieldwork in terms of time rather than space. 